\title{
A comparative study of metabolic profile in pre-eclampsia and normotensive preterm pregnancy
}

\author{
Durgavathi Kothapalli, Kameswari Kolluru*
}

Department of Obstetrics and Gynecology, Konaseema Institute of Medical Science Amalapuram, Andhra Pradesh, India

Received: 29 April 2021

Accepted: 28 May 2021

*Correspondence:

Dr. Kameswari Kolluru,

E-mail: k.kameswari@gmail.com

Copyright: () the author(s), publisher and licensee Medip Academy. This is an open-access article distributed under the terms of the Creative Commons Attribution Non-Commercial License, which permits unrestricted non-commercial use, distribution, and reproduction in any medium, provided the original work is properly cited.

\section{ABSTRACT}

Background: Hypertensive disorders of pregnancy are important and common cause of severe acute morbidity, longterm disability and death among mothers and babies. The metabolic characteristics (hypertriglyceridemia, hyperinsulinemia, hyperuricemia, low $\mathrm{HDL}_{2}$ cholesterol) in pregnancy-induced hypertension resemble the main features of the "insulin resistance syndrome". This may result in endothelial cell dysfunction as evidenced by $\mathrm{PGI}_{2}$ suppression. We have designed this study with an objective to compare the metabolic parameters like fasting and post prandial blood glucose, fasting plasma insulin, HOMA-IR and lipid profile between pre-eclampsia and normotensive pregnant women at late preterm (32-36 weeks).

Methods: Based on enrolment criteria and statistical analysis 224 patients were enrolled in study during study period and divided in to two groups, group 1- normotensive subjects, group2- pre-eclampsia subjects. Various biochemical parameters and obstetric profile was measured and compared with standard normotensive subjects.

Results: The mean fasting plasma insulin was significant higher in group 2 than group $1(18.36 \pm 6.48 \mathrm{mIU} / \mathrm{dl}$ versus $3.42 \pm 1.68 \mathrm{mIU} / \mathrm{dl})(\mathrm{p}=0.0001)$. The mean value of HOMA-IR was significant higher in group 2 than group $1(3.82 \pm 1.68$ versus $1.98 \pm 1.68)(\mathrm{p}=0.0001)$. The mean value of HDL was significant higher in group 1 than group $2(42.56 \pm 3.28$ $\mathrm{mg} / \mathrm{dl}$ versus $34.26 \pm 3.63 \mathrm{mg} / \mathrm{dl})(\mathrm{p}=0.0001)$. The mean concentration of LDL was significant higher in group 2 than group $1(142.23 \pm 24.36 \mathrm{mg} / \mathrm{dl}$ vrsus $84.32 \pm 18.24 \mathrm{mg} / \mathrm{dl})(\mathrm{p}=0.0001)$.

Conclusions: Systolic and diastolic blood pressure was significantly higher in preeclampsia patients and plasma fasting glucose was higher in normotensive subjects. In present study fasting plasma insulin and HOMA-IR are significantly higher in cases then control. Dyslipidemia is significantly evident in preeclampsia patients in our study.

Keywords: Dyslipidemia, Insulin resistance, Preeclampsia

\section{INTRODUCTION}

Hypertensive disorders of pregnancy are important and common cause of severe acute morbidity, long-term disability and death among mothers and babies. This group of disorder includes pre-eclampsia and eclampsia, gestational hypertension and chronic hypertension. It affects $10 \%$ pregnant of all pregnant women. Out of these pre eclampsia affects 2 to $8 \%$ of all pregnancies and remains a leading cause of maternal and perinatal morbidity and mortality worldwide. ${ }^{1-3}$ Pre eclampsia is defined as new onset hypertension and proteinuria developing in the second half of pregnancy and resolving after delivery. It has been reported in various literature that metabolic abnormalities, including dyslipidaemia, insulin resistance, and inflammatory markers, are also characteristic of pre eclampsia in addition to pathological abnormalities. ${ }^{4}$ Hauth et al has reported that midtrimester maternal insulin resistance is associated with subsequent preeclampsia. ${ }^{5}$ Kaaja et al has reported that the metabolic characteristics (hypertriglyceridemia, hyperinsulinemia, hyperuricemia, low $\mathrm{HDL}_{2}$ cholesterol) in pregnancyinduced hypertension resemble the main features of the "insulin resistance syndrome". This may result in 
endothelial cell dysfunction as evidenced by $\mathrm{PGI}_{2}$ suppression. ${ }^{6}$ If we can identify the metabolic disorder and pregravid BMI and hypercholesterolemia we can reduce the risk of hypertensive disorder of pregnancy. ${ }^{7,8}$ There is also inconsistency in the result of various study. Some study has reported that insulin resistance and metabolic disorder is associated with milder form of pre eclampsia as it is multi factorial disorder. ${ }^{9-11}$ But Stekkinger et al have concluded that the prevalence of the metabolic syndrome postpartum is twice as high in women with a history of early-onset compared to late-onset vascular-complicated pregnancy. ${ }^{12}$

Based on various literature reviews we have designed this study with an objective to compare the metabolic parameters like fasting and post prandial blood glucose, fasting plasma insulin, HOMA-IR and lipid profile between pre-eclampsia and normotensive pregnant women at late preterm (32-36 weeks).

\section{METHODS}

\section{Place of study}

Present study has been conducted in the department of obstetrics and gynaecology Konaseema institute of medical science Amalapuram Andhra Pradesh India.

\section{Duration of study}

It has been conducted from December 2018 to march 2021.

\section{Type of study}

This was a prospective comparative study.

\section{Ethics}

This study was approved by institutional ethics committee. A written informed consent was taken from all patients before enrolling them for study.

\section{Selection of patients}

Pregnant women with pre eclampsia in late preterm (32 to 36 weeks) admitted of attending OPD of obstetrics department were enrolled for this study based on following inclusion and exclusion criteria. Similarly normotensive pregnant women in late pregnancy were enrolled as per same inclusion and exclusion criteria.

\section{Inclusion criteria}

Pregnant women between 18 to 35 years of age. Diagnosed case of preeclampsia with singleton pregnancy in late preterm (32 to 36 weeks). Normotensive singleton pregnancy in late preterm (32 to 36 weeks).

\section{Exclusion criteria}

Patient with gestational diabetes mellitus, cardiovascular disorder, renal disease, immunological disorder, PCOS and other pre-existing metabolic disorder. Multiple pregnancies. Pregnancy with anaemia.

\section{Sample size}

Based on above mentioned criteria and statistical analysis 224 patients were enrolled in study during study period and divided in to two groups, group 1-normotensive subjects, group 2- pre-eclampsia subjects.

\section{Method}

During the study period of two years and three month 224 subjects were enrolled for present and divided in to two groups. Group 1: normotensive singleton pregnancy in late preterm (32 to 36 weeks), group 2: singleton pregnancy in late preterm ( 32 to 36 weeks) with clinical presentation of pre eclampsia, systolic blood pressure to $>140 \mathrm{mmHg}$, diastolic pressure $>90 \mathrm{mmHg}$ and proteinuria

A detailed history of present pregnancy and previous pregnancy in multiparous was taken. Height and weight of patient was noted from antenatal record and weight gain was noted from previous record. BMI was calculated. Palpatory method and auscultatory method was used for measurement of blood pressure in supine and sitting position. Systolic BP was taken by Korotkoff sound (phase I) and diastolic BP was taken by Korotkoff sound (phase V).

Hypertension was defined as a "diastolic blood pressure of at least $90 \mathrm{mmHg}$ or a systolic pressure of at least 140 $\mathrm{mmHg}$ or an increase in the former of at least $15 \mathrm{mmHg}$ or in the latter of $30 \mathrm{mmHg}$ on 2 occasions that were more than 4 hours apart or a single diastolic blood pressure reading of $110 \mathrm{mmHg}$ or greater" as per World Health Organization. ${ }^{13}$

$3 \mathrm{ml}$ of blood sample will be drawn from all the subjects following an overnight fast of 8 to 10 hours. Various parameter like, fasting plasma glucose, post prandial plasma glucose, HDL-C, LDL-c, TG total cholesterol, fasting plasma insulin, and HOMA-IR were measured. Hexokinase method was used for estimation of plasma glucose. For total cholesterol, we used Liebermann Burchard reaction colorimetric method; triglyceride was estimated by method of Neri and Fringe. HDL concentration was estimated by precipitation method. LDL concentration was calculated by WHO formula, LDL cholesterol $=$ total cholesterol - TG/5 - HDL $(\mathrm{mg} / \mathrm{dl}){ }^{14}$ Plasma insulin was determined by using enzyme linked immunosorbent assay. HOMA-IR was calculated by using this formula $(\mathrm{FPI} \times \mathrm{FPG}) / 22.5$. $^{15}$ 


\section{Sample size calculation}

Based on mean and standard deviation of previous studies, at $95 \%$ confidence intervals, $80 \%$ power and ratio of sample as 1, the sample size for finding the mean difference among two groups were computed to be 56. A total sample size of 112 was taken, assuming equal group sizes. ${ }^{16}$

\section{Statistical analysis}

Data were recorded in excel sheet and statistical analysis was done with software SPSS-14 version. Qualitative data were calculated as percentage and proportions and were analysed by Chi-square test. Quantitative data were expressed as mean \pm SD and these data were analysed by unpaired student $\mathrm{t}$ test.

\section{RESULTS}

During the study period of two years we have enrolled 112 patients in both groups as per inclusion and exclusion criteria.

As per Table 1 regarding demographic and obstetric profile of patients, number of patients below 20 years of age in group were 20 in group 1 and 10 in group 2. Number of subjects between 21 to 25 years was $44(39.28 \%)$ in group 1 and $32(28.57 \%)$ in group 2, between 26 to 30 years was $36(32.14 \%)$ in group 1 and $52(46.42 \%)$ in group 2 and above 31 years were was $12(10.71 \%)$ in group 1 and $28(25 \%)$ in group 2 . This distribution of age group is statistically significant. The mean age of patients in group 1 was $24.96 \pm 13.05$ years and group 2 was $26.66 \pm 5.16$ years this difference is not significant statistically $(\mathrm{p}=0.169)$.

In present study most of the patients were primi and gravida 1 . Subjects with parity 0 were $65(58.03 \%)$ in group 1 and $75(66.96 \%)$ in group 2, parity 1 were 35 $(31.25 \%)$ in group 1 and $30(26.78 \%)$ in group 2 and parity 2 were $12(10.71 \%)$ in group 1 and $7(6.25 \%)$ in group 2 . Both groups are comparable to each other $(\mathrm{p}=0.29)$. In our study, $74(66.07 \%)$ subjects in group 1 and $78(69.64 \%)$ subjects in group 2 were gravida 1, $32(28.57 \%)$ subjects in group 1 and $32(28.57 \%)$ subjects in group 2 were gravida 2 and $6(5.35 \%)$ subjects in group 1 and $2(1.17 \%)$ subjects in group 2 were gravida 3 . Both groups are comparable to each other $(\mathrm{p}=0.34)$. The BMI of both group are comparable to each other statistically $(22.52 \pm 1.35$ versus 24.005 \pm 2.88$)(\mathrm{p}=0.252)$ but mean BMI of group 2 is greater than group 1. Most of the patients in this study were in $35^{\text {th }}$ and $36^{\text {th }}$ week of gestation but there was no statistically significant difference between groups $(\mathrm{p}=0.15)$.

Table 1: Demography and obstetric profile of subjects.

\begin{tabular}{|c|c|c|c|c|}
\hline Variables & & Group 1 & Group 2 & P value \\
\hline \multirow{4}{*}{ Age } & less than 20 & $20(17.85 \%)$ & $10(8.92 \%)$ & \multirow{4}{*}{0.0027} \\
\hline & 21 to 25 & $44(39.28 \%)$ & $32(28.57 \%)$ & \\
\hline & 26 to 30 & $36(32.14 \%)$ & $52(46.42 \%)$ & \\
\hline & 31 to 35 & $12(10.71 \%)$ & $28(25 \%)$ & \\
\hline Mean age & & $24.96 \pm 13.05$ & $26.66 \pm 5.16$ & 0.169 \\
\hline \multirow{3}{*}{ Parity } & 0 & $65(58.03 \%)$ & $75(66.96 \%)$ & \multirow{3}{*}{0.29} \\
\hline & 1 & $35(31.25 \%)$ & $30(26.78 \%)$ & \\
\hline & 2 & $12(10.71 \%)$ & $7(6.25 \%)$ & \\
\hline \multirow{3}{*}{ Gravida } & 1 & $74(66.07 \%)$ & $78(69.64 \%)$ & \multirow{3}{*}{0.34} \\
\hline & 2 & $32(28.57 \%)$ & $32(28.57 \%)$ & \\
\hline & 3 & $6(5.35 \%)$ & $2(1.17 \%)$ & \\
\hline BMI $\left(\mathrm{kg} / \mathrm{m}^{2}\right)$ & & $22.52 \pm 1.35$ & $24.005 \pm 2.88$ & 0.252 \\
\hline \multirow{5}{*}{$\begin{array}{l}\text { Week of } \\
\text { gestation }\end{array}$} & 32 & $8(6.67 \%)$ & $4(3.57 \%)$ & \multirow{5}{*}{0.15} \\
\hline & 33 & $6(5.35 \%)$ & $8(6.67 \%)$ & \\
\hline & 34 & $22(19.64 \%)$ & $12(10.71 \%)$ & \\
\hline & 35 & $36(32.14 \%)$ & $46(41.07 \%)$ & \\
\hline & 36 & $40(35.71 \%)$ & $50(44.64 \%)$ & \\
\hline
\end{tabular}

As per Table 2, systolic and diastolic blood pressure was significantly higher in group 2 then group 1 . The mean $\mathrm{SBP}$ was $122.12 \pm 5.80 \mathrm{mmHg}$ in group 1 and $152.2 \pm 9.23$ $\mathrm{mmHg}$ in group $2(\mathrm{p}=0.0001)$. The mean DBP was $81.26 \pm 4.80 \mathrm{mmHg}$ in group 1 and $94.82 \pm 3.93 \mathrm{mmHg}$ in group $2(\mathrm{p}=0.0001)$. The mean fasting plasma glucose was significant higher in group 1 than group $2(86.03 \pm 3.33$ $\mathrm{mg} / \mathrm{dl}$ versus $82.88 \pm 4.38 \mathrm{mg} / \mathrm{dl})(\mathrm{p}=0.0001)$. The mean fasting plasma insulin was significant higher in group 2 than group $1 \quad(18.36 \pm 6.48 \mathrm{mIU} / \mathrm{dl}$ versus $3.42 \pm 1.68$ $\mathrm{mIU} / \mathrm{dl})(\mathrm{p}=0.0001)$. The mean value of HOMA-IR was significant higher in group 2 than group $1(3.82 \pm 1.68$ versus $1.98 \pm 1.68)(\mathrm{p}=0.0001)$. The mean value of HDL was significant higher in group 1 than group $2(42.56 \pm 3.28$ 
$\mathrm{mg} / \mathrm{dl}$ versus $34.26 \pm 3.63 \mathrm{mg} / \mathrm{dl})(\mathrm{p}=0.0001)$. The mean concentration of LDL was significant higher in group 2 than group $1(142.23 \pm 24.36 \mathrm{mg} / \mathrm{dl}$ versus $84.32 \pm 18.24$ $\mathrm{mg} / \mathrm{dl})(\mathrm{p}=0.0001)$. The mean concentration of triglyceride was significant higher in group 2 than group 1 $(196.32 \pm 18.86 \mathrm{mg} / \mathrm{dl}$ versus $112.28 \pm 21.26 \mathrm{mg} / \mathrm{dl})$ $(\mathrm{p}=0.0001)$. The mean concentration of total cholesterol was significant higher in group 2 than group 1 $(184.36 \pm 28.86 \mathrm{mg} / \mathrm{dl}$ versus $152.48 \pm 30.46 \mathrm{mg} / \mathrm{dl})$ $(\mathrm{p}=0.0001)$.

Table 2: Metabolic profile of subject under study.

\begin{tabular}{|llll|}
\hline Variables & Group 1 & Group 2 & P value \\
\hline SBP (mmHg) & $122.12 \pm 5.80$ & $152.2 \pm 9.23$ & 0.0001 \\
\hline DBP & $81.26 \pm 4.80$ & $94.82 \pm 3.93$ & 0.0001 \\
\hline FPG (mg/dl) & $86.03 \pm 3.33$ & $82.88 \pm 4.38$ & 0.02 \\
\hline FPI (mIU/dl) & $3.42 \pm 1.68$ & $18.36 \pm 6.48$ & 0.0001 \\
\hline HOMA-IR & $1.98 \pm 1.68$ & $3.82 \pm 1.68$ & 0.0001 \\
\hline HDL (mg/dl) & $42.56 \pm 3.28$ & $34.26 \pm 3.63$ & 0.0001 \\
\hline LDL (mg/dl) & $84.32 \pm 18.24$ & $142.23 \pm 24.36$ & 0.0001 \\
\hline TG (mg/dl) & $112.28 \pm 21.26$ & $196.32 \pm 18.86$ & 0.0001 \\
\hline $\begin{array}{l}\text { Total Ch. } \\
\text { (mg/dl) }\end{array}$ & $152.48 \pm 30.46$ & $184.36 \pm 28.86$ & 0.0001 \\
\hline
\end{tabular}

\section{DISCUSSION}

In present study metabolic parameters of preeclampsia and normotensive pregnant subjects are compared. There was statistically significant difference between two group regarding age distribution between two group. Pre eclampsia patients were most commonly above 26 years of age and mean age of pregnant women with preeclampsia was higher than normotensive pregnant women but not significant statistically $(\mathrm{p}=0.169)$. Lamminpää et al has concluded that preeclampsia is more common in women with advanced maternal age. Advanced maternal age is an independent risk factor for adverse outcomes in first-time mothers with preeclampsia. This finding supports our study. ${ }^{17}$ But Gandhi et al has reported that preeclampsia is more common below 20 years age and the mean age of cases (21.16 years) was less than the controls (23.56 years), this contradicts our study. ${ }^{18}$ In present study most of the patients were primi and gravida 1, this finding corroborates with the study of Kirsten et al. ${ }^{19}$ The mean BMI of group 2 was greater than group 1 but not significant statistically. Most of the patients in this study were in $35^{\text {th }}$ and $36^{\text {th }}$ week of gestation but there was no statistically significant difference between groups $(\mathrm{p}=0.15)$. Motedayen et al from his meta-analysis study has concluded that the results of this study revealed that there was a significant relationship between BMI and the risk of preeclampsia, so it can be said that BMI may be one of the ways to diagnose preeclampsia. This finding support our study. ${ }^{20}$

Systolic and diastolic blood pressure was significantly higher in preeclampsia patients and plasma fasting glucose was higher in normotensive subjects. This finding is supported by the study of Singh et al. ${ }^{21}$

In present study fasting plasma insulin and HOMA-IR were significantly higher in cases then control. Abhari et al has concluded that insulin-resistance of the group with preeclampsia was higher in first trimester prior to diagnosis as well as the third trimester after diagnosis compared to natural pregnancy under similar conditions. ${ }^{22}$ this finding support our study. Kaaja considered insulin resistance as a factor for preeclampsia pathogenesis which supports our study. ${ }^{6}$ But Sinha et al has concluded that Preeclampsia per se is not a risk factor for development of insulin résistance. This finding doesn't support our study. ${ }^{23}$

In our study we have we have observed that serum HDL was significantly lower in cases than control but serum LDL, TG and total cholesterol was significantly higher in preeclampsia patients. Gohil et al have concluded that dyslipidemia is significantly evident in preeclampsia and plays an important pathological role. The various causative factors for dyslipidemia and its prevention need to be further studied and evaluated. ${ }^{24}$ Mikhail et al has concluded that there is no direct relationship between triglyceride levels and severity of preeclampsia, this finding does not support our study. ${ }^{25}$

\section{CONCLUSION}

From present study we can conclude that pre eclampsia patients were most commonly above 26 years of age and mean age of pregnant women with preeclampsia was higher than normotensive pregnant women. In present study most of the patients were primi and gravida 1 . The mean BMI of preeclampsia patients were greater than normotensive pregnant subject but not significant statistically. Systolic and diastolic blood pressure was significantly higher in preeclampsia patients and plasma fasting glucose was higher in normotensive subjects. In present study fasting plasma insulin and HOMA-IR were significantly higher in cases than control. Dyslipidemia was significantly evident in preeclampsia patients in our study.

Funding: No funding sources

Conflict of interest: None declared

Ethical approval: The study was approved by the Institutional Ethics Committee

\section{REFERENCES}

1. Jeyabalan A. Epidemiology of preeclampsia: impact of obesity. Nutr Rev. 2013;71(1-01):S18-25.

2. Duley L. The global impact of pre-eclampsia and eclampsia. Semin Perinatol. 2009;33(3):130-7.

3. Steegers EA, von Dadelszen P, Duvekot JJ, Pijnenborg R. Pre-eclampsia. Lancet. 2010;376(9741):631-44. 
4. Burton GJ, Redman CW, Roberts JM, Moffett A. Pre-eclampsia: pathophysiology and clinical implications. BMJ. 2019;366

5. Hauth JC, Clifton RG, Roberts JM, Myatt L, Spong $\mathrm{CY}$, Leveno KJ, et al. Maternal insulin resistance and preeclampsia. Am J Obstet Gynecol. 2011;204:327.e1-6.

6. Kaaja R, Tikkanen MJ, Viinikka L, Ylikorkala O. Serum lipoproteins, insulin, and urinary prostanoid metabolites in normal and hypertensive pregnant women. Obstet Gynecol. 1995;85:353-6.

7. Thadhani R, Stampfer MJ, Hunter DJ, Manson JE, Solomon CG, Curhan GC. High body mass index and hypercholesterolemia: risk of hypertensive disorders of pregnancy. Obstet Gynecol. 1999;94:543-6.

8. D'Anna R, Baviera G, Corrado F, Giordano D, De Vivo A, Nicocia G, et al. Adiponectin and insulin resistance in early-and late-onset pre-eclampsia. BJOG Int J Obstet Gynaecol. 2006;113(11):1264-9.

9. Barry DR, Utzschneider KM, Tong J, Gaba K, Leotta DF, Brunzell JD, et al. Intraabdominal fat, insulin sensitivity, and cardiovascular risk factors in postpartum women with a history of preeclampsia. Am J Obstet Gynecol. 2015;213(1):104.e1-11.

10. Bartha JL, Romero-Carmona R, Torrejon-Cardoso R, Comino-Delgado R. Insulin, insulin like growth factor-1, and insulin resistance in women with pregnancy-induced hypertension. Am J Obstet Gynecol. 2002;187:735-40.

11. Caruso A, Ferrazzani S, De Carolis S, Lucchese A, Lanzone A, De Santis L, et al. Gestational hypertension but not pre-eclampsia is associated with insulin resistance syndrome characteristics. Hum Reprod. 1999;14:219-23.

12. Stekkinger E, Zandstra M, Peeters LL, Spaanderman ME. Early-onset preeclampsia and the prevalence of postpartum metabolic syndrome. Obstet Gynecol. 2009;114:1076-84.

13. Conde-Agudelo A, Villar J, Lindheimer M. World Health Organization systematic review of screening tests for preeclampsia. Obstet Gynecol. 2004;104(6):1367-91.

14. Friedewald WT, Levy RI, Fredrickson DS. Estimation of the concentration of low-density lipoprotein cholesterol in plasma, without use of the preparative ultracentrifuge. Clin Chem. 1972;18(6):499-502.

15. Matthews DR, Hosker JP, Rudenski AS, Naylor BA, Treacher DF, Turner RC. Homeostasis model assessment: insulin resistance and $\beta$-cell function from fasting plasma glucose and insulin concentrations in man. Diabetologia. 1985;28(7):4129.

16. Dhand NK, Khatkar MS. Statulator: An online statistical calculator. Sample Size Calculator for Comparing Two Independent Means. 2014. Available at: http://statulator.com/SampleSize/ss2M.html. Accessed 28 April 2021

17. Lamminpää R, Vehviläinen-Julkunen K, Gissler M, Heinonen S. Preeclampsia complicated by advanced maternal age: a registry-based study on primiparous women in Finland 1997-2008. BMC Pregnanc Childbirth. 2012;11(12):47.

18. Ramesh K, Gandhi S, Rao V. Socio-demographic and other risk factors of pre eclampsia at a tertiary care hospital, karnataka: case control study. J Clin Diagn Res. 2014;8(9):JC01-4.

19. Kirsten D, Deborah H. Risk factors for pre-eclampsia at antenatal booking: systematic review of controlled studies. BMJ. 2005;330:565

20. Motedayen M, Rafiei M, Rezaei Tavirani M, Sayehmiri K, Dousti M. The relationship between body mass index and preeclampsia: A systematic review and meta-analysis. Int $\mathbf{J}$ Reprod Biomed. 2019;17(7):463-72.

21. Singh MM. Carbohydrate metabolism in preeclampsia. Br J Obstet Gynaecol. 1976;83(2):124-31.

22. Abhari FR, Ghanbari Andarieh M, Farokhfar A, Ahmady S. Estimating rate of insulin resistance in patients with preeclampsia using HOMA-IR index and comparison with nonpreeclampsia pregnant women. BioMed Res Int. 2014;2014.

23. Sinha S, Singh GP, Gupta K, Kumar S, Gupta A. Effect of preeclampsia on insulin sensitivity. Int $\mathrm{J}$ Appl Basic Med Res. 2014;4(1):7-10.

24. Gohil JT, Patel PK, Gupta P. Estimation of lipid profile in subjects of preeclampsia. J Obstet Gynaecol India. 2011;61(4):399-403.

25. Mikhail MS, Basu J, Palan PR, Furgiuele J, Romney SL, Anyaegbunam A. Lipid profile in women with preeclampsia: relationship between plasma triglyceride levels and severity of preeclampsia. J Assoc Acad Minor Phys. 1995;6(1):43-5.

Cite this article as: Kothapalli D, Kolluru K. A comparative study of metabolic profile in preeclampsia and normotensive preterm pregnancy. Int J Reprod Contracept Obstet Gynecol 2021;10:2754-8. 